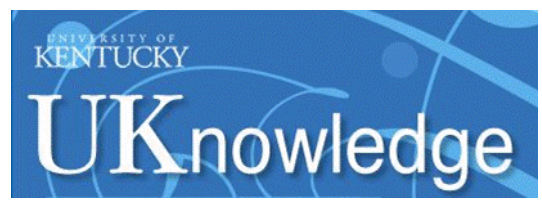

University of Kentucky

UKnowledge

\title{
Evaluation of a Community-Based Positive Youth Development Program for Adolescents with Greater Psychosocial Needs: Views of the Program Participants
}

\author{
Daniel T. L. Shek \\ University of Kentucky \\ Cecilia M. S. Ma \\ The Hong Kong Polytechnic University, China \\ Moon Y. M. Law \\ The Hong Kong Polytechnic University, China \\ Zoe Zhao \\ The Hong Kong Polytechnic University, China
}

Follow this and additional works at: https://uknowledge.uky.edu/pediatrics_facpub

Part of the Child Psychology Commons, Chinese Studies Commons, Community-Based Learning Commons, Developmental Psychology Commons, and the Mental and Social Health Commons

Right click to open a feedback form in a new tab to let us know how this document benefits you.

\section{Repository Citation}

Shek, Daniel T. L.; Ma, Cecilia M. S.; Law, Moon Y. M.; and Zhao, Zoe, "Evaluation of a Community-Based Positive Youth Development Program for Adolescents with Greater Psychosocial Needs: Views of the Program Participants" (2017). Pediatrics Faculty Publications. 277.

https://uknowledge.uky.edu/pediatrics_facpub/277

This Article is brought to you for free and open access by the Pediatrics at UKnowledge. It has been accepted for inclusion in Pediatrics Faculty Publications by an authorized administrator of UKnowledge. For more information, please contact UKnowledge@lsv.uky.edu. 


\section{Evaluation of a Community-Based Positive Youth Development Program for Adolescents with Greater Psychosocial Needs: Views of the Program Participants}

Digital Object Identifier (DOI)

https://doi.org/10.1515/ijdhd-2017-7007

Notes/Citation Information

Published in International Journal on Disability and Human Development, v. 16, issue 4, p. 387-393.

(C2017 Walter de Gruyter GmbH, Berlin/Boston.

The copyright holder has granted the permission for posting the article here.

This article is available at UKnowledge: https://uknowledge.uky.edu/pediatrics_facpub/277 
Daniel T.L. Shek*, Cecilia M.S. Ma, Moon Y.M. Law and Zoe Zhao

\section{Evaluation of a community-based positive youth development program for adolescents with greater psychosocial needs: views of the program participants}

DOI 10.1515/ijdhd-2017-7007

Received July 20, 2016; accepted August 20, 2016; previously published online January 26, 2017

\begin{abstract}
The present study attempted to investigate the perceptions of Chinese secondary school students with greater psychosocial needs of the Tier 2 Program in the community-based phase of P.A.T.H.S. Project in Hong Kong $(n=4245)$. Using a subjective outcome evaluation tool (Form C), the results revealed that a great majority of the students held positive attitudes toward the program, implementers and the effectiveness of the program. Also, the three domains of the program ("program quality", "implementer quality" and "program effectiveness") were significantly associated with each other. In line with previous findings, both program content and program implementer quality were significant predictors of program effectiveness. The current findings further reinforce the thesis that the community-based Tier 2 programs of the P.A.T.H.S. Project are effective in promoting the holistic development of adolescents with greater psychosocial needs in Hong Kong.
\end{abstract}

Keywords: Chinese adolescents; positive youth development; program evaluation; problem behavior; Project P.A.T.H.S.

\footnotetext{
*Corresponding author: Daniel T.L. Shek, Chair Professor of Applied Social Sciences and Associate Vice President, The Hong Kong Polytechnic University, Hung Hom, Hong Kong, P.R. China; Centre for Innovative Programmes for Adolescents and Families, The Hong Kong Polytechnic University, Hong Kong, P.R. China; Department of Social Work, East China Normal University, Shanghai, P.R. China; Kiang Wu Nursing College of Macau, Macau, P.R. China; and Division of Adolescent Medicine, Department of Pediatrics, Kentucky Children's Hospital, University of Kentucky School of Medicine, Lexington, KY, USA,

E-mail: daniel.shek@polyu.edu.hk

Cecilia M.S. Ma, Moon Y.M. Law and Zoe Zhao: Department of Applied Social Sciences, The Hong Kong Polytechnic University, Hong Kong, P.R. China
}

\section{Introduction}

Adolescents are typically at risk of engaging in developmental problems including substance abuse, criminal behavior, mental health and unhealthy lifestyles such as underage smoking, drinking and moral issues $[1,2]$. Such developmental problems adversely affect adolescent development on multiple levels, including physical, psychological, emotional, social and spiritual domains, which may eventually adversely affect social stability [3].

For instance, bullying behavior in school is a widespread problem with roughly $25 \%-30 \%$ of students involved in bullying in each school year [4]. A national study among US adolescents showed that the prevalence of having bullied others or having been bullied physically, verbally, socially and electronically at school for at least once in the last 2 months was 20.8\%, 53.6\%, 51.4\% and $13.6 \%$, respectively [5]. Besides, cyberbullying or electronic bullying is emerging with the rapid development of technology [6, 7]. After reviewing 35 articles in this field, research showed that approximately $24 \%$ of youth had been cyberbullied [8]. In recent years, researchers have demonstrated many harmful effects of bullying on adolescent school achievement, pro-social skills and psychological well-being $[9,10]$. Previous research also found that risk factors for being bullied included poor academic achievement, unhealthy friendship and peer relationships, bad communication with parents and being isolated [11]. Furthermore, youth who were victimized were at a greater risk of developing psychosocial and internalizing problems [12]. Particularly, cyberbullying victims were more likely to be isolated, felt hopeless and reported severe depressive symptoms [13]. Recognizing these complex and urgent problems, various school-based programs using different prevention approaches have been developed to reduce bullying and other aggressive behaviors among adolescents. A recent systematic metaanalytic review of anti-bullying program evaluation in school showed that the average reduction in bullying and victimization in these programs was 20\%-23\% [14]. 
Another example of adolescent developmental issues is substance abuse. Results from a national comorbidity adolescent survey found that alcohol and drug use were quite common in the US, with $78.2 \%$ of adolescents consuming alcohol and about $16.4 \%$ indulging in illicit drug abuse [15]. A study using meta-analysis to examine the effectiveness of drug treatment programs showed that although most types of treatment had a short-term effect in reducing substance abuse, smaller long-term improvement outcomes were reported [16]. Turning to Hong Kong, based on the result of students' drug use survey released in 2015 by the Narcotics Division of the Hong Kong Special Administrative Government, although there was a drop in lifetime prevalence in drug-taking amongst students, $0.7 \%, 2.2 \%$ and $2.5 \%$ of students in upper primary, secondary and post-secondary levels reported to have abused drugs, respectively. Moreover, the number of abusers of cannabis increased to $59.1 \%$. Compared with the results of the survey in 2011, most of the adolescent abusers (80.9\%) still never sought help from others [17].

In view of the existing adolescent developmental problems, minimizing the occurrence of adolescent problem behaviors and helping them develop in a healthy manner is of critical importance. An alternative approach, which is different from the past and centered on pathologies and problems of adolescents, has been proposed with a focus on addressing positive youth development (PYD) [18]. PYD emphasizes discovering and developing adolescents' talents, strengths, future potentials and interests [19]. As a strategy to facilitate the healthy growth of youth development and positive health outcomes, the support for PYD has been endorsed by the Division of Reproductive Health at the Disease Control and Prevention Centers in the USA [20].

In the process of becoming an adult, youth developmental challenges include identity formation, career exploration and increased social responsibility. Hence, programs should be designed to meet adolescent developmental needs and promote their psychosocial competences [21]. Through a review of 77 existing PYD programs, Catalano et al. [22] identified 15 PYD constructs that were commonly covered in successful PYD programs. These constructs included "bonding, resilience, social competence, recognition of positive behavior, emotional competence, cognitive competence, behavioral competence, moral competence, self-determination, self-efficacy, clear and positive identity, beliefs in the future, prosocial involvement, prosocial norms and spirituality".

While PYD programs were built and implemented in the West [23], the literature review revealed that systematic, multi-year and evidence-based PYD programs are lacking in Hong Kong [24]. Against this backdrop, using the 15 PYD constructs as the conceptual framework, a multi-year project entitled Positive Adolescent Training through Holistic Social Programs (Project P.A.T.H.S.) was launched in 2005. The project was funded by The Hong Kong Jockey Club Charities Trust (HK\$400 million) in collaboration with the Research Team, the Education Bureau (formerly Education and Manpower Bureau) and the Social Welfare Department. With the involvement of roughly half of the Hong Kong secondary schools, this PYD programs has been successfully implemented since 2005/2006 school year, with very encouraging evaluation findings [25]. From 2009 to 2010 school year, the HKCCT earmarked additional funding (HK\$350 million) to further promote a 3-year extension of the P.A.T.H.S. Project.

One unique feature of this PYD project is that several evaluation methods have been applied to examine the impact of the project [26]. Various evaluative strategies have been used to examine the project, including subjective outcome evaluation based on program participants and program implementers, objective outcome evaluation, qualitative evaluation, process evaluation, classroom observations, repertory grid tests and student products such as students' weekly diaries and drawings [27]. According to the results from eight waves of data collected over five consecutive years, the program showed a positive impact in promoting youth holistic development and preventing youth problem behaviors [28]. With the great success in the school-based program, a communitybased project was implemented in 2013 lasting until the end of 2017.

The P.A.T.H.S. Project consists of two tiers of programs. Based on a systematic, evidence-based and comprehensive curriculum that normally provides $10-20 \mathrm{~h}$ training for the students each year, the Tier 1 program is developed for Secondary 1-3 students. The Tier 2 program is developed for students in each grade with greater psychosocial needs [27]. As previous research on bullying intervention programs suggested that victimization is mainly influenced by parents and friends [6] and that programs with parental involvement are more effective [29], programs involving parents are also designed. Hence, participants of the community-based Tier 2 program are different from those of school-based programs. In the past years, while students, implementers and parents were involved in some programs, there were some programs that engaged only students or both students and implementers.

It is noteworthy that under the community-based phase, non-governmental organizations (NGOs) were also 
involved in the Tier 2 program. The NGOs took the responsibility to plan the most appropriate programs to meet participants' needs. Previous studies showed that changing of social systems could successfully affect adolescents [29]. In the community-based phase, different programs aiming to strengthen adolescent psychosocial competence were developed [30]. Generally speaking, various program modes were developed in the Tier 2 Program. These included "adventure-based counseling programs" (ABC), "voluntary training and service programs" (VTS), programs with both $\mathrm{ABC}$ and VTS elements and programs with other elements such as parental involvement [31]. The results of data analyses of 153,761 students in previous Tier 2 programs suggested that most of the students regarded the program as successful in promoting their holistic development [25].

To replicate the previous findings and to examine program effectiveness among participants in the community-based implementation phase, the subjective outcome evaluation approach was used to examine participants' views of the program. As an economical and efficient tool, subjective outcome evaluation is commonly used to investigate client satisfaction [32]. Typically, participants are asked questions including "whether they are satisfied with the program and whether they perceive the program to be beneficial to them". To assess the influence of different aspects of the program (such as implementers' qualities, content, time arrangement and effectiveness of the program) on participants' perceptions, client satisfaction scales with different dimensions were used [33]. Previous research showed that reports completed by the program implementers could reveal program effectiveness [34]. Besides, objective outcome and subjective outcome ratings were significantly correlated.

In this study, a subjective outcome evaluation scale (Form C) was given to the students after completing the whole program. In previous studies, the factor structure and reliability of Form $\mathrm{C}$ were established [35].

Based on the above background, the following research questions were proposed in the present study:

1. What are the perceptions of the program participants toward the Tier 2 program in the community-based P.A.T.H.S. Program? Previous results consistently revealed that the perceptions of the program participants were positive [25]. Hence, we expected similar findings in this study (Hypothesis 1).

2. Are there any inter-relationships amongst the three aspects (program qualities, implementers qualities and program effectiveness) assessed by Form C? Previous studies showed significant relationships among these three dimensions [36]. Therefore, we also expected significant relationships among these dimensions (Hypotheses 2a, 2b and 2c).

3. Do perceived program quality and perceived implementer quality predict participants' views on the effectiveness of the program? Based on previous findings [36], we hypothesized that these two qualities would predict perceived effectiveness of the program (Hypotheses 3a and 3b).

\section{Methods}

The participants of the current study were Secondary 1-Secondary 3 students showing greater psychosocial needs. From 78 schools and 15 community centers, 4245 participants took part in the Tier 2 Program of the Project P.A.T.H.S. in 2015. Among all of the participants, there were about 2739 in Secondary 1, 1848 in Secondary 2 and the rest 658 from Secondary 3.

To examine the participants' perception of the program, the Research Team developed a detailed and clear manual including the procedures and instructions for students to complete the evaluation form (Form C). An e-learning platform documenting all the procedures and instructions was also designed for collecting evaluation data using Form C. Once the program is finished, Form $\mathrm{C}$ was given to the students to complete. In the present study, a total of $3958 \mathrm{com}$ pleted questionnaires were collected.

\section{Instruments}

Comprising both rating scales and open-ended questions, the present study adopted a subjective outcome evaluation form (Form C) in the Tier 2 Program. Focus on understanding participants' perceptions, several major aspects including program content, implementer performance and program effectiveness were examined in Form C. For the structured assessment items, the present study used a 6-point scale (1= "strongly disagree"; 6 = "strongly agree").

\section{Data analyses}

Descriptive statistics were used to examine the percentages of students' perceptions of the three dimensions of the program ("program qualities", "implementer qualities" and "program effectiveness") in Form C. Reliability analysis was conducted to investigate the internal consistency of the scale. Pearson correlation analyses were performed to examine the inter-relationships amongst the three dimensions. Finally, multiple regression analyses were used to find whether the program and implementer qualities could predict the effectiveness of the program.

\section{Results}

Using descriptive data analysis, the current study examined the percentages of responses toward program qualities, implementer 
qualities and program effectiveness based on Form C. Results revealed that a great majority of the students held positive attitudes toward the program. Results in Table 1 showed that overall 95.4\% respondents were satisfied with the program and perceived that "the activities were carefully planned" (95.3\%). Approximately $94.8 \%$ of the respondents gave high recognition for the program. In Table 2, the same positive findings could be found regarding the participants' perceptions of the implementers. About 95.9\% participants were satisfied with the workers and perceived that they had professional knowledge and well prepared for the program. Views toward program effectiveness also showed positive results (Table 3): $94.2 \%$ of the respondents felt that the program was beneficial to their problem-solving ability; $94 \%$ of them believed that the program could help their development (94.0\%).

Reliability analyses (Table 4) showed that program content $(\alpha=0.96)$, program implementers $(\alpha=0.96)$ and program effectiveness $(\alpha=0.96)$ subscales as well as the total scale of Form $C$ were reliable $(\alpha=0.97)$. Regarding the inter-relationships among the items on "program content" (eight items), "program implementers" (eight items) and "program effectiveness" (eight items), Pearson correlation analyses (Table 5) showed correlation between "program content" and "program effectiveness" $(\mathrm{r}=0.65, \mathrm{p}<0.001)$, "program implementers" and "program effectiveness" $(\mathrm{r}=0.65$, $\mathrm{p}<0.001)$ and "program content" and "program implementers" $(\mathrm{r}=0.77, \mathrm{p}<0.001)$ in different grades.

Finally, multiple regression findings in Table 6 showed that program content (S1: $\beta=0.50, p<0.001$; $2: \beta=0.35, p<0.001$; S3: $\beta=0.21, p<0.001$; overall: $\beta=0.38, p<0.001)$ and the program implementers (S1: $\beta=0.36, p<0.001$; S2: $\beta=0.25, p<0.001$; S3: $\beta=0.53$, $\mathrm{p}<0.001$; overall: $\beta=0.35, \mathrm{p}<0.001$ ) were significant predictors of program effectiveness.

\section{Discussion}

Based on the data analyses of Form $\mathrm{C}$ collected from secondary school students with greater psychosocial needs,

Table 1: Comparison of the positive views toward Tier 2 Program across different grades.

\begin{tabular}{|c|c|c|c|c|c|c|c|c|}
\hline & \multicolumn{8}{|c|}{ Participants with positive responses across different grades } \\
\hline & \multicolumn{2}{|r|}{ S1 } & \multicolumn{2}{|r|}{ S2 } & \multicolumn{2}{|r|}{ S3 } & \multicolumn{2}{|c|}{ Overall } \\
\hline & $\mathbf{n}$ & $\%$ & $\mathrm{n}$ & $\%$ & $\mathbf{n}$ & $\%$ & $\mathbf{n}$ & $\%$ \\
\hline 1. The activities were carefully planned & 2396 & 94.9 & 803 & 95.9 & 573 & 96.3 & 3772 & 95.3 \\
\hline 2. The quality of the service was high & 2385 & 94.4 & 795 & 95.0 & 571 & 96.0 & 3751 & 94.8 \\
\hline $\begin{array}{l}\text { 3. The service provided could meet the } \\
\text { participants' needs }\end{array}$ & 2390 & 94.6 & 783 & 93.5 & 569 & 95.6 & 3742 & 94.5 \\
\hline $\begin{array}{l}\text { 4. The service delivered could achieve the } \\
\text { planned objectives }\end{array}$ & 2385 & 94.4 & 791 & 94.5 & 567 & 95.3 & 3743 & 94.6 \\
\hline 5. I could get the service I wanted & 2361 & 93.5 & 793 & 94.7 & 569 & 95.6 & 3723 & 94.1 \\
\hline 6. I had much interaction with other participants & 2375 & 94.0 & 796 & 95.1 & 570 & 95.8 & 3741 & 94.5 \\
\hline $\begin{array}{l}\text { 7. I would recommend others who have similar } \\
\text { needs to participate in the program }\end{array}$ & 2329 & 92.2 & 786 & 93.9 & 570 & 95.8 & 3685 & 93.1 \\
\hline 8. On the whole, I am satisfied with the service & 2398 & 94.9 & 801 & 95.7 & 577 & 97.0 & 3776 & 95.4 \\
\hline
\end{tabular}

All items are on a 6-point Likert scale with $1=$ strong disagree, 2 = disagree, $3=$ slightly disagree, $4=$ slightly agree, $5=$ agree, $6=$ strongly agree. Only respondents with positive responses (Options 4-6) are shown in the table.

Table 2: Comparison of the positive views toward implementers of the Tier 2 Program across different grades.

\begin{tabular}{|c|c|c|c|c|c|c|c|c|}
\hline & \multicolumn{8}{|c|}{ Participants with positive responses across different grades } \\
\hline & \multicolumn{2}{|r|}{ S1 } & \multicolumn{2}{|r|}{$\mathbf{S 2}$} & \multicolumn{2}{|r|}{ S3 } & \multicolumn{2}{|c|}{ Overal } \\
\hline & $\mathbf{n}$ & $\%$ & $\mathbf{n}$ & $\%$ & n & $\%$ & $\mathbf{n}$ & $\%$ \\
\hline 1. The worker(s) has (have) professional knowledge & 2408 & 95.3 & 811 & 96.9 & 575 & 96.6 & 3794 & 95.9 \\
\hline 2. The worker(s) demonstrated good working skills & 2401 & 95.1 & 805 & 96.2 & 580 & 97.5 & 3786 & 95.7 \\
\hline 3. The worker(s) was (were) well prepared for the program & 2414 & 95.6 & 806 & 96.3 & 577 & 97.0 & 3797 & 95.9 \\
\hline 4. The worker(s) understood the needs of the participants & 2396 & 94.9 & 797 & 95.2 & 574 & 96.5 & 3767 & 95.2 \\
\hline 5. The worker(s) cared about the participants & 2407 & 95.3 & 805 & 96.2 & 573 & 96.3 & 3785 & 95.6 \\
\hline 6. The worker(s)' attitudes were very good & 2403 & 95.1 & 806 & 96.3 & 581 & 97.6 & 3790 & 95.8 \\
\hline 7. The worker(s) had much interaction with participants & 2360 & 93.4 & 800 & 95.6 & 574 & 96.5 & 3734 & 94.3 \\
\hline 8. On the whole, I am satisfied with the worker(s) & 2415 & 95.6 & 802 & 95.8 & 579 & 97.3 & 3796 & 95.9 \\
\hline
\end{tabular}

All items are on a 6-point Likert scale with $1=$ strong disagree, 2 = disagree, $3=$ slightly disagree, $4=$ slightly agree, $5=$ agree, $6=$ strongly agree. Only respondents with positive responses (Options 4-6) are shown in the table. 
Table 3: Comparison of the positive views toward the effectiveness of the Tier 2 Program across different grades.

\begin{tabular}{|c|c|c|c|c|c|c|c|c|}
\hline & \multicolumn{8}{|c|}{ Participants with positive responses across different grades } \\
\hline & \multicolumn{2}{|r|}{ S1 } & \multicolumn{2}{|r|}{$\mathbf{S 2}$} & \multicolumn{2}{|r|}{ S3 } & \multicolumn{2}{|c|}{ Overal } \\
\hline & $\mathbf{n}$ & $\%$ & $\mathbf{n}$ & $\%$ & $\mathbf{n}$ & $\%$ & $\mathbf{n}$ & $\%$ \\
\hline 1. The service has helped me a lot & 2351 & 93.1 & 789 & 94.3 & 564 & 94.8 & 3704 & 93.6 \\
\hline 2. The service has enhanced my growth & 2358 & 93.3 & 799 & 95.5 & 565 & 95.0 & 3722 & 94.0 \\
\hline 3. In the future, I would receive similar service(s) if needed & 2323 & 92.0 & 780 & 93.2 & 570 & 95.8 & 3673 & 92.8 \\
\hline 4. I have learned how to help myself through participating in the program & 2355 & 93.2 & 795 & 95.0 & 562 & 94.5 & 3712 & 93.8 \\
\hline 5. I have had positive change(s) after joining the program & 2358 & 93.3 & 792 & 94.6 & 563 & 94.6 & 3713 & 93.8 \\
\hline $\begin{array}{l}\text { 6. I have learned how to solve their problems through participating in the } \\
\text { program }\end{array}$ & 2368 & 93.7 & 793 & 94.7 & 568 & 95.5 & 3729 & 94.2 \\
\hline 7. My behavior has become better after joining this program & 2312 & 91.5 & 780 & 93.2 & 560 & 94.1 & 3652 & 92.3 \\
\hline $\begin{array}{l}\text { 8. Those who know me agree that this program has induced positive } \\
\text { changes in me }\end{array}$ & 2306 & 91.3 & 788 & 94.1 & 561 & 94.3 & 3655 & 92.3 \\
\hline
\end{tabular}

All items are on a 6-point Likert scale with $1=$ strong disagree, 2 = disagree, $3=$ slightly disagree, $4=$ slightly agree, $5=$ agree, $6=$ strongly agree. Only respondents with positive responses (Options 4-6) are shown in the table.

Table 4: Mean, standard deviations, Cronbach's $\alpha$ s and mean of inter-item correlations among the variables by grade.

\begin{tabular}{|c|c|c|c|c|c|c|c|c|}
\hline & \multicolumn{2}{|r|}{ S1 } & \multicolumn{2}{|r|}{ S2 } & \multicolumn{2}{|r|}{ S3 } & \multicolumn{2}{|r|}{ Overal } \\
\hline & $M(S D)$ & $\alpha\left(\right.$ Mean $\left.^{\mathrm{a}}\right)$ & $M(S D)$ & $\alpha\left(\right.$ Mean $\left.^{\mathrm{a}}\right)$ & $M(S D)$ & $\alpha\left(\right.$ Mean $\left.^{\mathrm{a}}\right)$ & $M(S D)$ & $\alpha\left(\right.$ Mean $\left.^{\mathrm{a}}\right)$ \\
\hline Program content (eight items) & $4.98(0.83)$ & $0.96(0.73)$ & $4.93(0.84)$ & $0.96(0.75)$ & $4.99(0.78)$ & $0.96(0.75)$ & $4.97(0.83)$ & $0.96(0.73)$ \\
\hline Program implementers (eight items) & $5.10(0.83)$ & $0.96(0.76)$ & $5.10(0.83)$ & $0.97(0.79)$ & $5.11(0.78)$ & $0.96(0.76)$ & $5.10(0.82)$ & $0.96(0.77)$ \\
\hline Program effectiveness (eight items) & $4.94(0.87)$ & $0.96(0.74)$ & $4.95(0.81)$ & $0.96(0.75)$ & $5.01(0.77)$ & $0.96(0.73)$ & $4.95(0.84)$ & $0.96(0.74)$ \\
\hline Total effectiveness (24 items) & $5.01(0.76)$ & $0.97(0.61)$ & $4.99(0.70)$ & $0.97(0.55)$ & $5.04(0.70)$ & $0.98(0.62)$ & $5.01(0.74)$ & $0.97(0.60)$ \\
\hline
\end{tabular}

${ }^{a}$ Mean inter-item correlations.

Table 5: Correlation coefficients on the relationship between program components and program effectiveness by grade.

\begin{tabular}{|c|c|c|c|c|c|c|c|c|}
\hline \multirow[t]{2}{*}{ Variable } & \multicolumn{2}{|r|}{ S1 } & \multicolumn{2}{|r|}{$\mathbf{S 2}$} & \multicolumn{2}{|r|}{$\mathbf{S 3}$} & \multicolumn{2}{|c|}{ Overall } \\
\hline & 1 & 2 & 1 & 2 & 1 & 2 & 1 & 2 \\
\hline 1. Program content (eight items) & - & & - & & - & & - & \\
\hline 2. Program implementers (eight items) & $0.77^{\mathrm{a}}$ & - & $0.73^{\mathrm{a}}$ & - & $0.82^{\mathrm{a}}$ & - & $0.77^{\mathrm{a}}$ & - \\
\hline 3. Program effectiveness (eight items) & $0.69^{a}$ & $0.68^{\mathrm{a}}$ & $0.53^{\mathrm{a}}$ & $0.50^{\mathrm{a}}$ & $0.65^{\mathrm{a}}$ & $0.71^{\mathrm{a}}$ & $0.65^{\mathrm{a}}$ & $0.65^{\mathrm{a}}$ \\
\hline
\end{tabular}

${ }^{a} \mathrm{p}<0.001$.

Table 6: Multiple regression analyses predicting program effectiveness by grade.

\begin{tabular}{|c|c|c|c|c|}
\hline & & Predictors & & Model \\
\hline & Program content & Program implementers & & \\
\hline & $\boldsymbol{\beta}^{\mathrm{a}}$ & $\beta^{a}$ & $\mathbf{R}$ & $\mathbf{R}^{2}$ \\
\hline S1 & $0.41^{b}$ & $0.36^{\mathrm{b}}$ & 0.73 & 0.53 \\
\hline $\mathrm{S} 2$ & $0.35^{b}$ & $0.25^{\mathrm{b}}$ & 0.56 & 0.31 \\
\hline S3 & $0.21^{b}$ & $0.53^{b}$ & 0.72 & 0.51 \\
\hline Overall & $0.38^{b}$ & $0.35^{\mathrm{b}}$ & 0.69 & 0.47 \\
\hline
\end{tabular}

a Standardized coefficients. ${ }^{\mathrm{b}} \mathrm{p}<0.001$. the present study was aimed to explore the effectiveness of the Tier 2 Program in the community-based phase of the P.A.T.H.S. Project in Hong Kong. As previous research suggested that PYD programs led to better outcomes for at-risk youth [37], it was expected that students joining the program would experience program benefits of the Tier 2 Program. There are several special features of the present study. First, this study used data collected from the community-based P.A.T.H.S. Project. The findings showed that the P.A.T.H.S. Tier 2 Program was equally effective in both school-based and community-based contexts. Second, the 
current study utilized the Form $\mathrm{C}$ that was found to have good psychometric properties [35]. Third, a large sample $(n=4245)$ participated in this study. Fourth, in view of the lack of empirical research in the field of communitybased PYD programs in the Chinese context, this study can be regarded as a pioneering attempt, which makes an important contribution to the Chinese literature on PYD programs.

With regard to the descriptive statistical analyses, several observations deserve attention. The current findings suggest that positive attitudes toward the Tier 2 program could be found in the majority of students. Hence, Hypothesis 1 was supported. Specifically, more than $90 \%$ of the participants said that "they were satisfied with the service" and they highly recognized the program to be well-designed and implemented. Besides, positive attitudes could be found on the students' perceptions of program implementers and program effectiveness. In particular, an overwhelming majority of the students viewed that through joining the program, their problem-solving skills as well as self-help skills improved. These benefits are of paramount importance for healthy youth development. For instance, previous research suggested that problem-solving abilities were negatively associated with the development of anxiety and depression [38]. Problemsolving skills also prevented youth violence [39].

Consistent with previous studies, findings based on internal consistency and Pearson correlation analyses revealed that Form $C$ is valid and reliable. In particular, Pearson correlation analyses suggest that there were significant inter-correlations among the three dimensions (i.e. "program quality", "implementer qualities" and "program effectiveness") across the three grade levels. The present findings are in line with the findings in previous studies [25, 31] and they provide support for Hypotheses $2 \mathrm{a}, 2 \mathrm{~b}$ and $2 \mathrm{c}$.

Considering the predictors of perceived program effectiveness, findings are consistent with our expectation. As both program content and program implementer quality were significant predictors of program effectiveness, findings are in line with the previous findings [36]. Hence, Hypotheses $3 \mathrm{a}$ and $3 \mathrm{~b}$ were supported. With respect to the program content in the community-based Tier 2 program, a different program content based on the experiential learning approach was used to design different topic-related activities to help students strengthen their competence, cultivate their social responsibility and promote prosocial behaviors. Besides, consistent with previous studies, quality of program implementers was also a significant predictor of participants' rating of program effectiveness. Thus, the current findings suggest that systematic training of program implementers, which would eventually shape program quality, should be stepped up in PYD programs.

Several limitations of this research should be noted. First, as only quantitative subjective outcome evaluation findings were presented in this study, qualitative subjective outcome evaluation findings should be presented in future. Second, only findings based on the perceptions of the student participants were discussed. Hence, it would be interesting to include data based on the perspective of the program implementers as well. Third, in line with previous studies [25,31], only perceptions of program content and implementer quality were considered as predictors in this study. This design may not be adequate and comprehensive enough. As such, other predictors such as parental involvement should be examined to explore their effect on program effectiveness in future research. Despite these limitations, the current findings provide further evidence suggesting that the community-based Tier 2 programs of the P.A.T.H.S. Project are effective in promoting holistic development of adolescents with greater psychosocial needs.

Acknowledgments: The preparation for this paper and the Project P.A.T.H.S. were financially supported by The Hong Kong Jockey Club Charities Trust.

\section{References}

1. Shek DT, Hing KM, Sun RC. A brief overview of adolescent developmental problems in Hong Kong. ScientificWorldJ 2011;11:2243-56.

2. Monahan KC. Adolescent pathways to co-occurring problem behavior: The effects of peer delinquency and peer substance use. J Res Adolesc 2014;24:630-45.

3. Shek DT, Yu L. Longitudinal impact of the project PATHS on adolescent risk behavior: what happened after five years? ScientificWorldJ 2012;2012:316029.

4. Book AS, Volk AA, Hosker A. Adolescent bullying and personality: an adaptive approach. Pers Individ Diff 2012;52:218-23.

5. Wang J, lannotti RJ, Nansel TR. School bullying among adolescents in the United States: physical, verbal, relational, and cyber. J Adolesc Health 2009;45:368-75.

6. Wang J, lannotti RJ, Luk JW. Patterns of adolescent bullying behaviors: Physical, verbal, exclusion, rumor, and cyber. J Sch Psychol 2012;50:521-34.

7. Mishna F. Risk factors for involvement in cyber bullying: victims, bullies and bully-victims. Child Youth Serv Rev 2012;34:63-70.

8. Cassidy W, Faucher C, Jackson M. Cyberbullying among youth: a comprehensive review of current international research and its implications and application to policy and practice. Sch Psychol Int 2013;34:575-612.

9. Mackie CJ. Adolescent bullying, cannabis use and emerging psychotic experiences: a longitudinal general population study. Psychol Med 2013;43:1033-44. 
10. Foshee VA. Bullying as a longitudinal predictor of adolescent dating violence. J Adolesc Health 2014;55:439-44.

11. Erignoz E. The role of parental, school, and peer factors in adolescent bullying involvement: results from the Turkish HBSC 2005/2006 Study. Asia-Pacific J Public Health 2015;27:NP1591-603.

12. Willford A. Effects of the KiVa anti-bullying program on adolescents' depression, anxiety, and perception of peers. J Abnorm Child Psychol 2012;40:289-300.

13. Wang J, Nansel TR, lannotti RJ. Cyber and traditional bullying: differential association with depression. J Adolesc Health 2011;48:415-7.

14. Ttofi MM. Farrington DP. Effectiveness of school-based programs to reduce bullying: a systematic and meta-analytic review. J Exp Criminology 2011;7:27-56.

15. Swendsen J. Use and abuse of alcohol and illicit drugs in US adolescents: results of the National Comorbidity Survey-Adolescent Supplement. Arch Gen Psychiatry 2012;69:390-8.

16. Tanner-smith EE, Wilson SJ, Lipsey MW. The comparative effectiveness of outpatient treatment for adolescent substance abuse: a meta-analysis. J Subst Abuse Treat 2013;44:145-58.

17. Narcotics Division. The $2014 / 15$ survey of drug use among students. Hong Kong, Narcotics Division, Security Bureau, The Government of the Hong Kong, Special Administrative Region, 2015. URL: http://www.nd.gov.hk/en/survey_of_drug_use_1415.htm.

18. Shek DT, Yu L. A review of validated youth prevention and positive youth development programmes in Asia. Int J Adolesc Med Health 2011;23:317-24.

19. Damon W. What is positive youth development? Ann Am Acad Political Soc Sci 2004;591:13-24.

20. Benson PL. Positive youth development: theory, research, and applications. New York: John Wiley, 2006.

21. Gavin LE. A review of positive youth development programs that promote adolescent sexual and reproductive health. J Adolesc Health 2010;46:75-91.

22. Catalano RF. Prevention science and positive youth development: competitive or cooperative frameworks? J Adolesc Health 2002;31:230-9.

23. Catalano RF, Berglund ML, Ryan JA, Lonczak HS, Hawkins JD. Positive youth development in the United States: research findings on evaluations of positive youth development programs. Ann Am Acad Political Soc Sci 2004;591:98-124.

24. Shek DT, Yu L. A review of validated youth prevention and positive youth development programmes in Asia. Int J Adolesc Med Health 2011;23:317-24.

25. Shek DT, Sun RC. Positive youth development programs for adolescents with greater psychosocial needs: subjective outcome evaluation over 3 years. J Pediatr Adolesc Gynecol 2014;27:17-25.

26. Shek DT. Evaluation of the Project PATHS using multiple evaluation strategies. In: Shek DT, Sun RC, editors. Development and evaluation of positive adolescent training through holistic social programs (PATHS). Singapore: Springer, 2013:53-67.

27. Shek DT, Sun RC. Evaluation of positive youth development programs that help secondary 2 students with greater psychosocial needs. Int Public Health J 2009;1:335-46.

28. Shek DT, Hing KM, Sun RC. Development of a new curriculum in a positive youth development program: the Project PATHS in Hong Kong. ScientificWorldJ 2011;11:2207-18.

29. Kim BK. Change in protective factors across adolescent development. J Appl Dev Psychol 2015;40:26-37.

30. Walker JS, Gowen LK. Community-based approaches for supporting positive development in youth and young adults with serious mental health conditions. Research and training center for pathways to positive futures. Portland, OR: Portland State University, 2011.

31. Shek DT, Ma C. Subjective outcome evaluation findings: factors related to the perceived effectiveness of the Tier 2 Program of the Project P.A.T.H.S. ScientificWorldJ 2010;10:250-60.

32. Carpenter AT, Carpenter VG. Reflections of client satisfaction: reframing family perceptions of mandatory alternative school assignment. J Instruct Psychol 2012;39:1-11.

33. Shek DT. Is subjective outcome evaluation related to objective outcome evaluation? Insights from a longitudinal study in Hong Kong. J Pediatr Adolesc Gynecol 2014;27:50-6.

34. Shek DT, Sun RC. Secondary data analyses of subjective outcome evaluation findings of the project PATHS in Hong Kong. ScientificWorldJ 2010;10:2101-11.

35. Shek DT, Ma CM, Siu AM. Validation of a subjective outcome evaluation tool for participants in a positive youth development program in Hong Kong. J Pediatr Adolesc Gynecol 2014;27:26-31.

36. Shek DT, Law MY. Evaluation of programs for adolescents with greater psychosocial needs: community-based Project PATHS in Hong Kong. Int J Adolesc Med Health 2016. DOI: 10.1515/ijamh2017-3004.

37. Sanders J, Munford R, Thimasarn-Anwar T. The role of positive youth development practices in building resilience and enhancing wellbeing for at-risk youth. Child Abuse Negl 2015;42:40-53.

38. Hui EK, Tsang SK, Law BC. Combating school bullying through developmental guidance for positive youth development and promoting harmonious school culture. ScientificWorld] 2012;5:2266-77.

39. Wilson CJ, Bushnell JA, Rickwood DJ. The role of problem orientation and cognitive distortions in depression and anxiety interventions for young adults. Adv Ment Health 2011;10:52-61. 